French budget

\section{More means less for research}

Rough estimates are emerging in Paris of the budget that the ministry of research and industry may enjoy next year. The expectation is that the budget will be 7 per cent up on 1983, in current francs, compared with official inflation of around 8 per cent. So the outlook is for a constant budget, more or less - except that true inflation is probably more like 10-11 per cent than the official estimates and that the slow slide of the franc against the dollar (and the mark and the Swiss franc) has increased the cost of imported materials and equipment and of French subscriptions to international laboratories.

Whatever the final version, the real significance of this budget is that the policies established by the previous research minister, and in particular the promise of a 17.8 per cent real rise in budgets each year, is no longer possible. In the months ahead, hard choices will be necessary and it is not yet clear what mechanisms there are to make them. The winners will probably be those fields which have the strongest lobbies at the ministry - biotechnology for example. What worries some in Paris is that there are too few lobbies for the system to arrive naturally at balanced policies,

\section{Europe follows US}

\section{Brussels}

THE Belgian Biochemical Society (SBB), this year responsible for organizing the fifteenth meeting of the Federation of European Biochemical Societies (FEBS) on 24-29 July, is in that delicate state of having arranged a party but of not knowing how well it will succeed. Although small by the standards of the now biennial meeting of the Federation of American Societies for Experimental Biology (FASEB), the FEBS meeting will probably attract 2,000 participants.

The organizers say they have tried to streamline this year's programme in the interests of direct communication between participants. One innovation is a jobplacement bureau along the lines of those accompanying major meetings of US societies. Professor Gisele Preaux of the University of Leuven, secretary of SBB, says that interest in the job-placement service has been greater than expected and that there is a plan to provide a permanent information system on the job market.

This year's FEBS meeting will have 200 invited speakers, including seven plenary addresses by Arthur Kornberg (Stanford), Christian de Duve (Rockefeller University), Zouhair Atassi (Mayo Clinic), Piet Borst (Amsterdam), Charles Weissmann (Zurich), Klaus Weber (Max Planck, Göttingen) and Aaron Klug (Cambridge). There will be 1,300 poster exhibits.

Geert Linnebank which sometimes happens in Washington. At the Centre National de la Recherche Scientifique (CNRS), the largest basic research agency in France, which is supported through the ministry, directorgeneral Pierre Papon hopes above all to hang on to the promised new posts for researchers. A 4.5 per cent increase each year had been planned under Jean-Pierre Chevènement, the previous research minister. "A few weeks ago, we were frightened we might get none", he said. "Now I am almost reassured." CNRS will not get its 4.5 per cent but it will at least get something.

\section{Computers in France \\ Beggars must buy Bull}

FRENCH high-energy physicists are "beggars in Hamburg and beggars at CERN" for large-scale computing, according to Professor Pierre Falk-Variant, scientific adviser to the director of the Institut $\mathrm{Na}$ tional de Physique Nucleaire et Physique des Particules $\left(\mathrm{IN}_{2} \mathrm{P}_{3}\right)$. The institute, financed by the Centre National de la Recherche Scientifique (CNRS), manages high-energy and nuclear physics in France.

"I am ashamed of my country in computing", Falk-Variant said in commenting on a recent report by an $\mathrm{IN}_{2} \mathrm{P}_{3}$ working group which showed that French physicists in these fields have access to "six units" of computing power compared with 30 units for their German colleagues and 24 units for the British. (The $\mathrm{IN}_{2} \mathrm{P}_{3}$ unit is based on the power of a single CDC 6600 computer and represents the operation of some 1.5-2 million instructions per second.) In the same terms, CERN (the European Organization for Nuclear Research) alone had 19 units of computer power in 1982.

Even in mini-computers, French physicists are falling behind, says the report. This state of affairs has a serious impact on international collaborations, which are now almost inevitable in highenergy physics experiments. "We fought like mad for 18 months to buy a VAX [built by the Digital Equipment Corporation]. When one of my collaborators wants a VAX, he simply signs an order. Here, after 18 months of asking for nine, we got two" says Falk-Variant. It is thus becoming increasingly difficult for French high-energy physicists to play their proper part in data processing in European experiments, even though it is only through data processing that the results of experiments emerge.

The problems facing the French physicists are not financial but commercial. The French Government seeks to help the national computer industry, now all gathered under one banner in the holding company "Bull". However, the physicists usually prefer American DEC, CDC and
Meanwhile, Papon is brooding about the problem of constant budgets. The best hope is that CNRS may get more than the overall 7 per cent when the ministry cake is divided. Otherwise, "we shall have to make cuts". CNRS priorities (not in order) are: life sciences, humanities and social sciences and the engineering sciences. And although high-energy physics is not a "top priority", Papon would be reluctant to see that field cut. This small mercy should be good news for the high-energy physicists, who are supported by CNRS through the Institut National de Physique Nucléaire et Physique des Particules, whimsically called IN $\mathbf{P}_{3}$. That enjoyed none of Jean-Pierre Chevènement's largesse and in fact suffered a cut in real terms this year.

Robert Walgate

IBM machines to French-built computers. Their collaborators use them and vast amounts of software, much of it developed at CERN, is freely available.

To change now to Bull machines would involve a tremendous waste of time, the physicists say. But it is beginning to seem as if they might have done better to write the new software, for the French Government has dug in its heels.

Strangely enough, the French Government has achieved this stranglehold on high-energy physicists without having an explicit policy to divert orders to Bull. The policy directive in force some years ago has lapsed in favour of "free competition", a Bull executive explained last week. But he added that it does not follow that individuals in government departments handling applications for computers "may not favour Bull"'

At the Ministry of Industry and Research, where the Mission de l'Informatique holds the real power by exercising a veto over computer purchases out of the public purse, the whole issue is now described as "very sensitive". A new policy is being formulated to plan the development of the Bull group but which should also appease the physicists and other academic users.

One possible solution suggested by Professor Pierre Papon, director-general of CNRS, to M. Laurent Fabius, minister of industry and research, is that CNRS and $I_{2} P_{3}$ computer specialists should play a greater role in Bull's research and development. This may be seen as a kind of quid pro quo for the right to buy the American computers that the physicists (and others) need now, and could improve Bull's market place in the long term.

Papon believes this scheme strikes a chord at Bull. The company's four-year plan, agreed earlier this year, already foresees a much greater degree of cooperation than hitherto between Bull and French researchers.

Robert Walgate 